\title{
Latent inhibition to a compound following exposure to the elements or the compound
}

\author{
ROBERTO ÁLVAREZ GÓMEZ and MATÍAS LÓPEZ RAMÍREZ \\ University of Oviedo, Oviedo, Asturias, Spain
}

(Vincent M. LoLordo, Sponsor)

\begin{abstract}
In this experiment, we analyzed the effects of preexposure to either a compound taste stimulus or its separate elements on the strength of the conditioned aversion resulting from pairing the compound with $\mathrm{LiCl}$. All animals drank the same amount of liquid during preexposure and conditioning. Compound preexposure produced more latent inhibition than did element preexposure with both a short $(4 \mathrm{~h})$ preexposure-conditioning interval and a long $(48 \mathrm{~h})$ one. These results are interpreted as reflecting generalization decrement.
\end{abstract}

Exposure to a flavor before aversive conditioning attenuates the aversion conditioned to that flavor. This phenomenon is an example of latent inhibition (Lubow, 1973). Several theories have tried to explain it without complete success (for a review, see Lubow, 1989). Some attempts to analyze latent inhibition have used a procedure in which, during the preexposure phase, another stimulus is presented in compound with the stimulus to be conditioned. For instance, Kaye, Swietalski, and Mackintosh (1988) found that the presence of the distractor stimulus decreased the latent inhibition effect (see also Best, Gemberling, \& Johnson, 1979; Honey \& Hall, 1988).

It has been suggested that when a compound is presented, a unique cue or configure emerges (see, e.g., Kehoe \& Gormezano, 1980; Razran, 1971; Rescorla, 1973). If a compound is indeed more than the simple sum of its elements, preexposure to both elements ought to produce less latent inhibition than should compound preexposure when the compound is conditioned, because of generalization decrement. That is, the strength of latent inhibition will be reduced if the stimulus used during conditioning differs in some way from the preexposed stimulus.

Holland and Forbes (1980) found that preexposure to the elements was more effective in producing latent inhibition to a compound than was preexposure to the compound itself. Their outcome is compatible with an associative point of view, in which stimuli in compound compete to acquire associative strength. If we assume that latent inhibition is the result of the acquisition of an associative

\footnotetext{
This research was supported by a B.F.P.I. (MEC, Spain) to the first author. We thank T. Fidler and V. M. LoLordo for their comments on the manuscript. Correspondence should be addressed to R. Álvarez Gómez or M. López Ramírez, Facultad de Psicología, Universidad de Oviedo, Aniceto Sela s/n, 33005 Oviedo, Spain.
}

conditioned response of inattention (Lubow, Schnur, \& Rifkin, 1976), then on the compound-conditioning trial, the total amount of such associative strength when the stimuli have been preexposed separately will be greater than when they have been preexposed in compound, because separately presented elements do not compete.

However, Baker, Haskins, and Hall (1990) obtained the opposite results in two experiments, one of which replicated Holland and Forbes's (1980) Experiment 2. Preexposure to both elements produced less latent inhibition to the compound than did compound preexposure.

López Ramírez and Aguado Aguilar (1992), using fewer preexposures to the compound or elements than did Baker et al. (1990), also evaluated the effects of the interval between preexposure and conditioning. With a long interval of $48 \mathrm{~h}$, they found no difference between the amounts of latent inhibition produced by preexposure to the compound or to the separate elements, but with a 4-h interval, they found more latent inhibition following compound preexposure, a result similar to that of Baker et al. (1990).

The objective in the present experiment was to gather more data on the relative effects of compound preexposure versus preexposure to the separate elements on latent inhibition of the compound. Unlike earlier experiments, preexposure and conditioning access to the solutions was limited so that all groups would consume the same amount. Rats had access to $8 \mathrm{ml}$ of the appropriate solution for $30 \mathrm{~min}$ in each preexposure and during conditioning. The design included six groups of subjects. Two groups (COM-4 and COM-48) were preexposed to a simultaneous compound of two flavors (coffee + vinegar), and another two groups (EL-4 and EL-48) were preexposed to the separate elements (coffee/vinegar). Two additional groups (CON-4 and $\mathrm{CON}-48$ ) served as control groups and received water during preexposure. For each type of preexposure, the separate groups received preexposureconditioning intervals of 4 and $48 \mathrm{~h}$, respectively. 


\section{METHOD}

\section{Subjects and Apparatus}

Forty-eight male Wistar rats with a mean weight of $402 \mathrm{~g}$ (range $317-463 \mathrm{~g}$ ) were used. The rats were 100 days old at the beginning of the experiment. The animals were housed in individual cages $(27 \times$ $27 \times 15 \mathrm{~cm}$ ), with food available ad lib. The solutions were presented in glass bottles with stainless steel spouts. The stimuli used were vine$\operatorname{gar}(1 \% \mathrm{wt} / \mathrm{vol})$ and coffee $(1 \% \mathrm{wt} / \mathrm{vol})$, and the compound stimulus was a mixture of both. The toxic agent unconditioned stimulus (US) was a $0.15-\mathrm{M}$ solution of $\mathrm{LiCl}$, administered at doses of $6 \mathrm{ml} / \mathrm{kg}$ body weight.

\section{Procedure}

The animals were progressively adapted to a water deprivation schedule, during which they had access to a bottle of water in daily periods of $10 \mathrm{~min}$ for 10 days. The subjects were divided into six groups differing in preexposure procedure (elements, compound, or no preexposure) and duration of the interval between preexposure and conditioning ( 4 or $48 \mathrm{~h}$ ). Animals of groups COM-48 and COM-4 were given two 30-min preexposure trials with $8 \mathrm{ml}$ of a simultaneously presented compound of coffee and vinegar. Groups EL- 48 and EL- 4 had access to $8 \mathrm{ml}$ of coffee or vinegar, each for a period of $30 \mathrm{~min}$, with order of presentation counterbalanced. Control groups $\mathrm{CON}-48$ and $\mathrm{CON}-4$ drank $8 \mathrm{ml}$ of water during each of the two periods. The interval between the first and second preexposures was $5 \mathrm{~h}$. Conditioning was done 4 or $48 \mathrm{~h}$ after the last preexposure for half of each group. Conditioning consisted of access to $8 \mathrm{ml}$ of the coffee-vinegar compound for $30 \mathrm{~min}$, followed immediately by an injection of $\mathrm{LiCl}(0.15 \mathrm{M}, 6 \mathrm{ml} / \mathrm{kg})$. On the next day, all rats drank water for $10 \mathrm{~min}$, and on the day after that, the test was done. During the test, the animals had access to the compound of coffee and vinegar for $10 \mathrm{~min}$.

\section{RESULTS}

Figure 1 shows consumption of the compound in the test by the different groups. An analysis of variance performed on the consumption data yielded a significant effect of the preexposure procedure $[F(2,48)=50.8, p<$ $.001]$, but there was neither a significant effect of interval $[F(1,48)=0.44, p>.05]$ nor a significant interaction of these factors $[F(2,48)=1.432, p>.05]$. Post

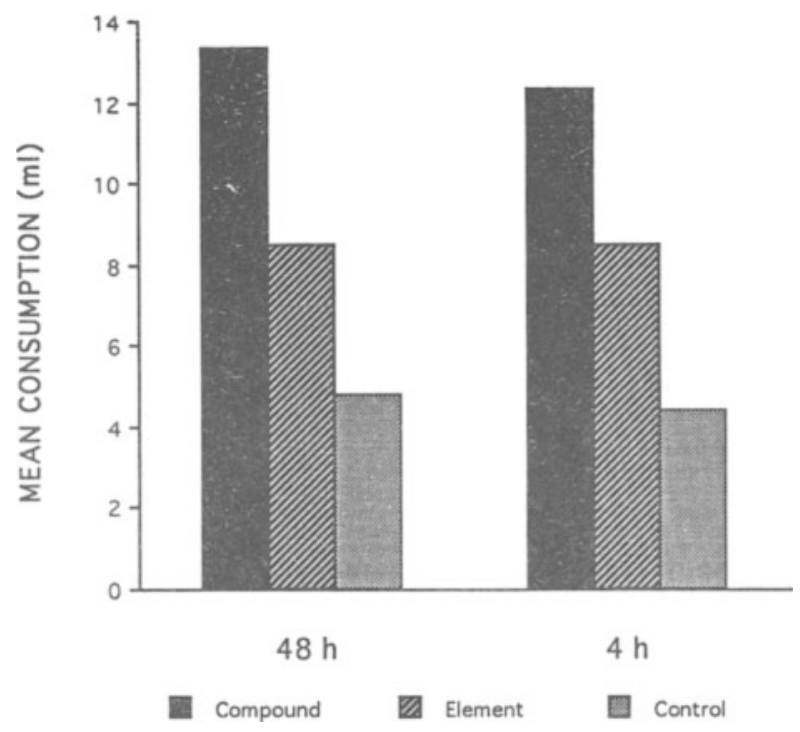

Figure 1. Mean consumption of the compound on the test day. hoc analyses (Newman-Keuls) showed that control groups $\mathrm{CON}-48$ and $\mathrm{CON}-4$ drank less than did the other groups. Groups COM-48 and COM-4 drank the same amount and drank more than did the EL-48 and EL-4 groups, which did not differ.

\section{DISCUSSION}

The results of this experiment indicate that, with a taste-aversion learning paradigm, taste-compound preexposure produces more latent inhibition on compound conditioning than does preexposure to the elements. These results agree with those reported by Baker et al. (1990) and López Ramírez and Aguado Aguilar (1992) but are contrary to the results of Holland and Forbes (1980). These results are not consistent with an associative account such as Lubow's (1989) conditioned-attention theory, which predicts greater latent inhibition from element preexposure than from compound preexposure. Instead, we could maintain that there is generalization decrement of latent inhibition in the group preexposed to the separate elements because a unique cue present on the compoundconditioning trial has not been preexposed. In the present experiment, the differential effect of compound and element preexposure was obtained with both a short (4-h) and a long (48-h) interval. López Ramírez and Aguado Aguilar (1992) found such an effect only with a short interval, whereas with a 48 -h preexposure-conditioning interval, the two preexposure treatments produced equivalent latent inhibition. We have no ready explanation of this discrepancy.

\section{REFERENCES}

Baker, A. G., Haskins, C. E. \& Hall, G. (1990). Stimulus generalization decrement in latent inhibition to a compound following exposure to the elements or the compound. Animal Learning \& Behavior, 18, $162-170$.

Best, M. R., Gemberling, G. A., \& Johnson, P. E. (1979). Disrupting the conditioned stimulus preexposure effect in flavor aversion learning: Effects of interoceptive distractor manipulations. Journal of Experimental Psychology: Animal Behavior Processes, 5, 321-334.

Holland, P. C., \& ForBes, D. T. (1980). Effects of compound or element preexposure on compound flavor aversion conditioning. Animal Learning \& Behavior, 8, 199-203.

HoNEY, R. C., \& HALL, G. (1988). Overshadowing and blocking procedures in latent inhibition. Quarterly Journal of Experimental Psychology, 40B, 163-186.

Kaye, H., Swietalski, N., \& Mackintosh, N. J. (1988). Distractor effects on latent inhibition are a consequence of generalization decrement. Quarterly Journal of Experimental Psychology, 40B, 151-161.

Kenoe, E. J., \& Gormezano, I. (1980). Configuration and combination laws in conditioning with compound stimuli. Psychological Bulletin, 87, 351-378.

López Ramírez, M. \& Aguado Aguilar, L. (1992). Effects of element or compound preexposure on taste-aversion learning with simultaneous and serial compounds. Bulletin of the Psychonomic Society, 30(4), 279-282.

Luвow, R. E. (1973). Latent inhibition. Psychological Bulietin, 79, 398-407.

LuBow, R. E. (1989). Latent inhibition and conditioned attention theory. Cambridge: Cambridge University Press.

Lubow, R. E., Schnur, P., \& Rifkin, B. (1976). Latent inhibition and conditioned attention theory. Journal of Experimental Psychology: Animal Behavior Processes, 2, 163-174.

Razran, G. (1971). Mind in evolution. New York: Appleton-Century Crofts.

Rescorla, R. A. (1973). Evidence for the "unique stimulus" account of configural conditioning. Journal of Comparative \& Physiological Psychology, 85, 331-338. 